\title{
The effect of Hippophae rhamnoides L. extract on acrylamide- induced brain injury in rats
}

\author{
Mehmet Ibrahim Turan ${ }^{*}$ (D), Mehmet Aktaş $^{2}$ (D), Betul Gundogdu ${ }^{3}$ (D), Sevil Karahan Yilmaz ${ }^{4}$ (D), \\ Halis Suleyman ${ }^{5}$ (D)
}

1. MD, Assistant Professor. Department of Pediatric Neurology - Faculty of Medicine - Gaziantep University - Gaziantep, Turkey.

2. PhD, Assistant Professor. Department of Biochemistry - Faculty of Medicine - Erzincan Binali Yildirim University - Erzincan, Turkey.

3. PhD, Assistant Professor. Department of Pathology - Faculty of Medicine - Ataturk University - Erzurum, Turkey.

4. PhD, Assistant Professor. Nutrition and Dietetics - Erzincan Binali Yildirim University - Erzincan, Turkey.

5. PhD, Professor. Department of Pharmacology - Faculty of Medicine - Erzincan Binali Yildirim University - Erzincan, Turkey.

\begin{abstract}
Purpose: Reactive oxygen species (ROS), interleukin-1 $\beta$ (IL-1 $\beta$ ) and tumor necrosis factor- $\alpha$ (TNF- $\alpha$ ) have been shown in the pathogenesis of acrylamide neurotoxicity. Hippophae rhamnoides L. extract (HRE) has a cytoprotective effect by stabilizing the production of ROS, IL-1 $\beta$ and TNF- $\alpha$. The objective of the article was to investigate the effect of HRE on acrylamide-induced brain damage in rats biochemically and histopathologically. Methods: To the HRE+acrylamide only (ACR) group ( $n=6)$ of the animals, HRE was administered orally at a dose of $50 \mathrm{mg} / \mathrm{kg}$ into the stomach by gavage. The same volume of solvent (olive oil) was administered orally to the ACR $(n=6)$ and healthy $(H G)(n=6)$ groups. One hour after HRE administration, acrylamide was given orally at a dose of $20 \mathrm{mg} / \mathrm{kg}$ to HRE+ACR and ACR groups in the same way. This procedure was repeated once a day for 30 days. At the end of this period, brain tissues extracted from animals killed with $50 \mathrm{mg} / \mathrm{kg}$ thiopental anesthesia were examined biochemically and histopathologically. Results: It has been shown that HRE prevents the increase of malondialdehyde (MDA), myeloperoxidase (MPO), IL-1 $\beta$ and TNF- $\alpha$ with acrylamide and the decrease of total glutathione (tGSH) and glutathione reductase (GSHRd) levels in brain tissue. Conclusion: HRE may be useful in the treatment of acrylamide-induced neurotoxicity.
\end{abstract}

Key words: Hippophae. Acrylamide. Brain Injuries. Toxicity. Rats.

*Corresponding author: turan78tr@hotmail.com | +905052604621

Received: June 02, 2021 | Review: Aug 01, 2021 | Accepted: Sept 04, 2021

Conflict of interest: Nothing to declare.

Research performed at Department of Pediatric Neurology, Faculty of Medicine, Gaziantep University, Gaziantep, Turkey. 


\section{Introduction}

Acrylamide (2-propenamid) is an active compound investigated among heat-induced food contaminants ${ }^{1}$. Several studies have reported that various food substances contain differing levels of acrylamide. High levels of acrylamide have been reported in fried and roasted food in particular ${ }^{2,3}$. Acrylamide has been documented to exhibit genotoxic, carcinogenic, neurotoxic, reproductive, and developmental effects ${ }^{4}$. Neurotoxicity is an adverse effect that creates damage in the peripheral and central nervous systems in humans and it is dose-dependent ${ }^{5}$. Lipid peroxidation and oxidative stress associated with excessive reactive oxygen species have been implicated in the pathogenesis of acrylamide neurotoxicity ${ }^{6}$. Tabeshpour et al. ${ }^{7}$ showed that acrylamide leads to oxidative brain damage by increasing malondialdehyde (MDA) production in brain tissue and reducing endogenous glutathione (GSH) production. Goudarzi et al. ${ }^{8}$ showed that acrylamide exhibits neurotoxic effects by increasing the production of both oxidants and proinflammatory cytokines such as interleukin-1 $\beta$ (IL-1 $\beta$ ) and tumor necrosis factor- $\alpha$ (TNF- $\alpha$ ).

Hippophae rhamnoides L. extract (HRE), whose protective effect against acrylamide-induced brain damage was investigated in this study, was obtained from the fruit of the Hippophae rhamnoides L. (HR) plant (sea buckthorn), a member of the Elaeagnaceae family. HR is traditionally well-known for its pharmacological activities ${ }^{9}$. It contains vitamins $A$ and $C$, alpha-tocopherol, large quantities of carotenoids, vitamin $\mathrm{E}$, minerals $\mathrm{K}, \mathrm{Na}, \mathrm{Mg}, \mathrm{Ca}, \mathrm{Fe}, \mathrm{Zn}$, and Se), monosaccharides, amino acids, flavonoids, fatty acids, glycerol phospholipids, phytosterols, zeaxanthin esters, and polyphenolic compounds ${ }^{10}$. These compounds in the plant exhibit antioxidant, anti-inflammatory, antibacterial, antineoplastic, immunomodulatory, and hepatoprotective effects. Previous studies have shown that HRE possesses potential free radical activity. In addition, HRE has also been reported to be a neuroprotectant against oxidative stress-related neurodegeneration ${ }^{9}$.

HRE has also been reported to exhibit a cytoprotective effect by stabilizing the production of reactive oxygen species (ROS), IL-1 $\beta$ and TNF- $\alpha^{11}$. This information from the literature indicates that HRE may be beneficial in the treatment of acrylamide-related brain damage. We encountered no previous studies investigating the effect of HRE on acrylamide-induced brain damage.

The purpose of this research was to perform a histopathological and biochemical investigation of the effect on acrylamide-induced brain damage in rats.

\section{Methods}

Animal experiments were performed in accordance with the national guidelines for the use and care of laboratory animals and were approved by the local animal ethics committee of Ataturk University, Erzurum, Turkey (Ethics Committee Number: 75296309-050.01.04-E.2000065782).

Eighteen male albino Wistar rats weighing 285-300 g were procured from the Ataturk University Medical and Experimental Application and Research Center, Erzurum. A seven-day acclimatization period was applied before starting the experiments. The animals were maintained in a 12 -h light/dark cycle (lights on 7 a.m. -7 p.m.) in an air-conditioned constant temperature $\left(22 \pm 1^{\circ} \mathrm{C}\right)$ colony room, with free access to water and $20 \%(\mathrm{w} / \mathrm{w})$ protein commercial chow.

\section{Experimental groups}

The experimental animals were divided into healthy $(H G)$, acrylamide only (ACR) and HRE + acrylamide (HRE+ACR) groups.

\section{Experimental protocol}

Animals in the HRE+ACR group $(n=6)$ received $50 \mathrm{mg} / \mathrm{kg}$ HRE by oral gavage. The ACR $(n=6)$ and $H G(n=6)$ groups received the same volume of solvent (olive oil to dilute HRE) by the oral route. One hour after HRE administration, the $\mathrm{HRE}+\mathrm{ACR}$ and $\mathrm{ACR}$ groups received $20 \mathrm{mg} / \mathrm{kg}$ acrylamide by the oral route using the same method. These procedures were repeated once daily for 30 days. At the end of that period, the animals were sacrificed under high-dose anesthesia (50 mg/kg thiopental sodium), and the brain tissues were removed and subjected to biochemical and histopathological examination ${ }^{12}$.

\section{Chemicals}

The thiopental sodium used in the experiments was obtained from IE Ulagay (Turkey), HRE from PhytoLab (Russia), and acrylamide from Sigma-Aldrich Chemical Company (United States of America).

\section{Biochemical procedures}

\section{Specimen preparation}

$\mathrm{A} \mathrm{pH}=6$ potassium phosphate buffer containing $0.5 \%$ hexadecyltrimethylammonium bromide was used for MPO assay in brain tissue. For MDA assay, $1.15 \%$ potassium chloride solution was made up to $2 \mathrm{~mL}$ in $\mathrm{pH}=7.5$ phosphate buffer for other measurements and homogenized in ice medium. These were than centrifuged at $10,000 \mathrm{rpm}$ for $10 \mathrm{~min}$ at $+4^{\circ} \mathrm{C}$. The supernatant part was used as the analysis specimen. 


\section{Malondialdehyde analysis}

MDA measurement was based on the method described by Ohkawa et al. ${ }^{13}$. This method relies on the absorbance of the pink-colored complex formed by thiobarbituric acid (TBA) with MDA at high temperature $\left(95^{\circ} \mathrm{C}\right)$ being read spectrophotometrically at a wavelength of $532 \mathrm{~nm}$. The homogenates were centrifuged at $5,000 \mathrm{~g}$ for $20 \mathrm{~min}$, and the resulting supernatants were used to calculate the amount of MDA.

\section{Myeloperoxidase analysis}

In order to perform the MPO assay in brain tissue homogenates, a $\mathrm{pH}=6$ phosphate buffer containing $0.5 \%$ hexadecyltrimethylammonium bromide was prepared. This was then centrifuged for $15 \mathrm{~min}$ at $10,000 \mathrm{rpm}$ at $+4^{\circ} \mathrm{C}$. The resulting supernatant part was used as an analysis specimen. The oxidation reaction with MPO-mediated $\mathrm{H}_{2} \mathrm{O}_{2}$ with 4-amino antipyrine/phenol solution as substrate was used to determine MPO enzyme activity ${ }^{14}$.

\section{$\underline{\text { Total glutathione analysis }}$}

The level of GSH in the total homogenate was measured using the method described by Lindsay and Sedlak with some modifications ${ }^{15}$. First, the sample was weighed and homogenized in $2 \mathrm{~mL}$ of $50 \mathrm{mmol} / \mathrm{L} \mathrm{Tris}-\mathrm{HCl}$ buffer containing $20 \mathrm{mmol} / \mathrm{L}$ ethylenediamine teatraacetic acid (EDTA) and $0.2 \mathrm{mmol} / \mathrm{L}$ sucrose at $\mathrm{pH}$ 7.5. The homogenate was next immediately precipitated with $0.1 \mathrm{~mL}$ of $25 \%$ trichloroacetic acid. The precipitate was removed after centrifugation at $4,200 \mathrm{rpm}$ for $40 \mathrm{~min}$ at $4^{\circ} \mathrm{C}$, and the supernatant was used for GSH level measurement.

\section{Glutathione reductase analysis}

Glutathione reductase (GSHRd) activity was determined spectrophotometrically by measuring the rate of nicotinamide adenine dinucleotide phosphate (NADPH) oxidation at $340 \mathrm{~nm}$ as described by Carlberg et al. ${ }^{16}$. Following tissue homogenization, supernatant was used for GSHRd measurement.

\section{$\underline{\mathrm{IL}-1} \beta \underline{\beta}$ and TNF- $\alpha \underline{\alpha \text { analysis in tissue }}$}

Tissue homogenate IL- $1 \beta$ and TNF- $\alpha$ concentrations were measured using rat-specific sandwich enzyme-linked immunosorbent assay (ELISA) Rat Interleukin $1 \beta$ (Cat. No. YHB0616Ra, Shanghai LZ) and Rat Tumor Necrosis Factor $\alpha$ ELISA (Cat. No. YHB1098Ra, Shanghai LZ) kits. Analyses were performed in line with the manufacturers' instructions. Briefly, monoclonal antibody specific for rat IL-1 $\beta$ and TNF- $\alpha$ were coated onto the wells of the microplates. The tissue homogenate, standards, and biotinylated monoclonal antibody specific and streptavidin-HRP were pipetted into these wells and then incubated at $37^{\circ} \mathrm{C}$ for $60 \mathrm{~min}$. After washing, chromogen reagent $A$ and chromogen reagent $B$ were added. The bound enzyme then reacted with the mixture to produce a color. The mixture was incubated at $37^{\circ} \mathrm{C}$ for $10 \mathrm{~min}$, after which stop solution was added. The intensity of this colored product was directly proportional to the concentration of rat IL-1 $\beta$ and TNF- $\alpha$ present in the original specimen. At the end of this procedure, the well plates were read at $450 \mathrm{~nm}$ using a microplate reader (Bio-Tek, United States of America). The absorbance of the samples was estimated with formulae using standard graphics.

\section{Histopathological examination}

All tissue samples were first identified in a $10 \%$ formaldehyde solution for light microscopic assessment. Following the identification process, the tissue samples were washed under tap water in cassettes for $24 \mathrm{~h}$. The samples were then treated with conventional grade of alcohol $(70,80,90$, and $100 \%)$ to remove the water within the tissues. The tissues were then passed through xylol and embedded in paraffin. Four-to-five micron sections were cut from the paraffin blocks and hematoxylin-eosin staining was administered. Their photos were taken following the Olympus DP2-SAL Firmware Program (Olympus ${ }^{\circledR}$ Inc., Tokyo, Japan) assessment. Histopathological assessment was performed by the pathologist blind for the study groups.

\section{Statistical analysis}

The experiment results were expressed as mean \pm standard error of the mean ( $X \pm S E M)$. The significance of differences between the groups was determined using the one-way analysis of variance (ANOVA) test, followed by the Tukey test. All statistical procedures were carried out on Statistical Package for Social Sciences 18.0 (Armonk, NY, United States of America) software, and $\mathrm{P}<0.05$ were regarded as significant.

\section{Results}

\section{Biochemical findings}

When the ACR group was compared with HG group, a significant increase in MDA levels and MPO activities were noted in brain tissues $(p<0.05)$. In the HRE+ACR group, the MDA levels and MPO activities were significantly decreased as compared to the ACR group ( $p<0.05)$ (Fig. 1). The level of $\mathrm{tGSH}$, a non-enzymatic endogenous antioxidant, was noted significant decrease in the ACR group in comparison to that in the HG group $(p<0.05)$. Similarly, GSHRd activities, an enzymatic antioxidant, were significantly lower in the ACR group as compared to that in the HG group $(p<0.05)$. 
In the comparison of ACR and HRE+ACR groups, both level of tGSH and GSHRd activities were elevated in favor of the HRE+ACR group (Fig. 2). Additionally, the levels of IL-1 $\beta$ and TNF- $\alpha$ were significantly higher in ACR groups $v s$. HG groups $(p<0.05)$. These levels were similar in both $H G$ and HRE+ACR groups (Fig. 3).
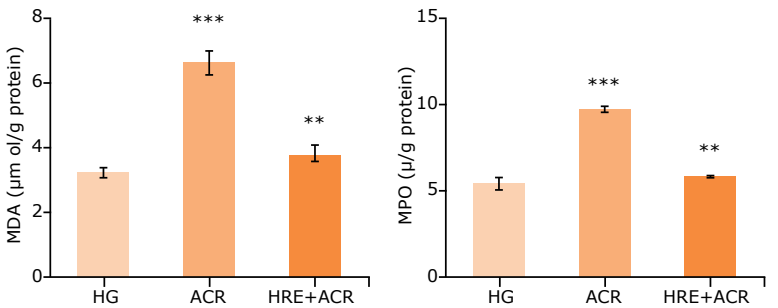

MDA: malondialdehyde; HG: healthy; ACR: acrylamide only; HRE: Hippophae rhamnoides L. extract; MPO: myeloperoxidase; $* * p<0.001$ according to the ACR group; ${ }^{* * *} p<0.001$ according to the HG group.

Figure 1 - MDA levels and activities of MPO in brain tissue of the study groups.
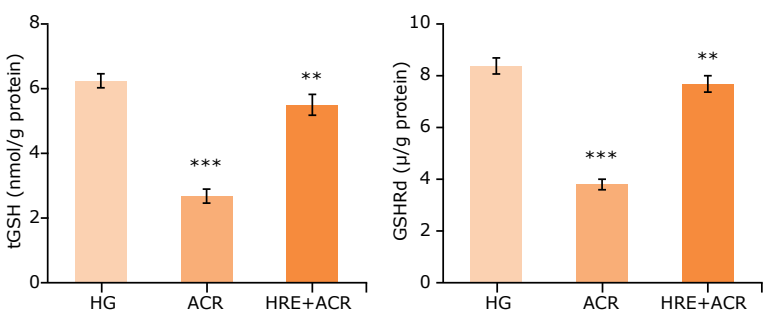

HG: healthy; ACR: acrylamide only; HRE: Hippophae rhamnoides L. extract; tGSH: decrease of total glutathione; GSHRd: glutathione reductase; $* * p<0.001$ according to the ACR group; ${ }^{* *} p<0.001$ according to the HG group.

Figure 2 - tGSH levels and activities of GSHRd in brain tissue of the study groups.
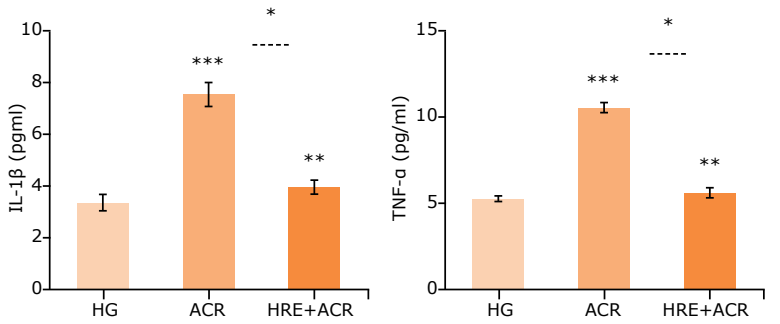

HG: healthy; ACR: acrylamide only; HRE: Hippophae rhamnoides L. extract; ${ }^{*} p<0.001$ according to the ACR group; $* * p<0.001$ according to the HG group; ***p $<0.001$ according to the HG group.

Figure 3 - Levels of IL-1 $\beta$ and TNF- $\alpha$ in brain tissue of the study groups.

\section{Histopathological findings}

As seen in Fig. 4a, no pathological findings were observed in the brain tissue of the HG group, except for mild congestion. However, significant inflammatory cell infiltrate and neovascularization were observed in the brain tissue of the ACR group, which received acrylamide (Fig. 4b). Mild signs of hemorrhage were detected in the brain tissue of the HRE+ACR group treated with HRE (Fig. 4C).
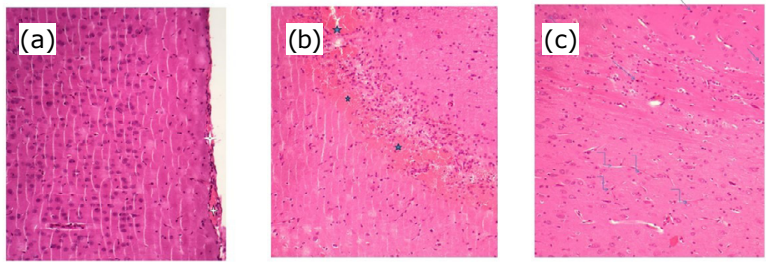

HG: healthy; H\&E: hematoxylin-eosin; HRE: Hippophae rhamnoides L. extract; ACR: acrylamide only.

Figure 4 - Histopathological appearance of brain tissue the study groups. (a) Brain tissue of the HG group: healthy brain tissue with mild congestion (star) (H\&E x200). In the section of the cerebral cortex, slight congestion is seen in the tissue structures. (b) Brain tissue of the HRE+ACR group: hemorrhage areas (star) (H\&E X200). (c) Brain tissue of the ACR group: inflammatory cell infiltration (arrow) and neovascularization (zigzag arrow) (H\&E X200).

\section{Discussion}

This study investigated the effect of HRE on acrylamideinduced oxidative stress-related neurotoxicity in brain tissue. Various studies have examined the mechanism involved in the central nervous system neurotoxicity caused by acrylamide. In the study of Yousef et al. ${ }^{17}$, it was suggested that excessive ROS production is one of the important factors underlying acrylamide neurotoxicity. In addition, it has been reported that oxidative stress is caused by the $L P O$ reaction due to $R O S$ production ${ }^{18}$. As it is known, LPO ends with the production of MDA. However, MDA is cytotoxic and leads to progressive aggravation of cell damage $^{19}$. In recent studies, the success in the treatment of oxidative damage is evaluated by the decrease in MDA leve ${ }^{20}$. In the study of Yanji et al. ${ }^{21}$, there is information that HRE protects the brain tissue from oxidative damage by reducing the increase in MDA due to toxic substances in the brain. The information obtained from the literature indicates that oxidative stress developed in the brain tissue, as the MDA level was increased in the acrylamide group compared to the healthy and HRE group.

MPO, which was also used in our study to evaluate acrylamide neurotoxicity, is an oxidant-effective enzyme secreted from azurophilic cells of polymorphonuclear leukocyte (PNL) and monocytes ${ }^{22}$. In the literature, there is information that MPO is held responsible in the pathogenesis of many inflammatory diseases, including cardiovascular, kidney, lung, rheumatoid arthritis, skin inflammation 
and neuronal ${ }^{23}$. The damaging effect of MPO on tissue is enhanced by the formation of hypochlorous acid from hydrogen peroxide and chloride ions ${ }^{24}$. The inhibition of MPO activity by acrylamide by HRE may be due to its inhibition of PNL leakage (infiltration) into the damaged area. It has been documented in previous studies that flavonoids in HRE reduce inflammatory neutrophil and macrophage counts and suppress cell infiltration ${ }^{25}$. The increase in MDA and MPO levels in this study shows that acrylamide-induced neurotoxicity occurs and it is consistent with the literature ${ }^{26}$.

In the literature, the importance of decreasing the intracellular GSH concentration as well as the increase of oxidants in acrylamide-related damage has been expressed ${ }^{18}$. The enzyme that maintains GSH in cells is GSHRd. Therefore, GSH and GSHRd together better protect cells from oxidative damage by $\mathrm{ROS}^{27}$. It is known that they provide this cytoprotective effect by converting free radicals and peroxides into harmless products ${ }^{28}$. Our experimental results and literature data show that oxidative stress developed in the brain tissue of the acrylamide group, while oxidative stress was suppressed in the HRE group. Gupta et al. ${ }^{29}$ showed that HRE protects brain tissue from toxic damage of ROS products with its antioxidant activity. In addition, it has been reported that HRE prevents the reduction of GSH and other enzymatic and nonenzymatic antioxidants against oxidative damage ${ }^{30}$. It has also been reported that HRE induces the production of GSHRd and other antioxidants ${ }^{31}$.

The role of proinflammatory IL-1 $\beta$ and TNF- $\alpha$ cytokine increase in the pathogenesis of neurotoxicity in the brain has been stated ${ }^{32}$. The fact that IL-1 $\beta$ and TNF- $\alpha$ levels were elevated in the acrylamide group in our study is consistent with studies showing inflammation in the pathogenesis of neurotoxicity ${ }^{33}$. The low levels of proinflammatory cytokines in the group receiving HRE are in line with the literature reporting its anti-inflammatory effect ${ }^{34}$. Decreased IL-1 $\beta$ and TNF- $\alpha$ levels due to suppression of nuclear factor kappa B (NF-kB) expression are held responsible for the anti-inflammatory mechanism of action of $\mathrm{HRE}^{35}$. HRE fruits have been reported to contain carotenes, fatty acids, and many water- and fat-soluble vitamins that have antioxidant, anti-inflammatory, and antiulcer IL-1 $\beta$ and TNF- $\alpha$ antagonist features ${ }^{36}$.

Histopathologically, neovascularization and inflammatory cell infiltrate were observed in the acrylamide group in which oxidant and proinflammatory cytokine levels were measured high. This shows that our biochemical test results are consistent with the histopathological findings. A number of inflammatory cells, including neutrophils, eosinophils, mast cells, macrophages, is known to be involved in inducing angiogenesis ${ }^{37}$. In addition, it is stated that the important link between inflammation and neovascularization is oxidative stress $^{38}$. No information was found in the literature to support the protective effect of HRE on acrylamide-induced neurotoxicity in brain tissue. However, there is information that HRE improves histopathological changes in the cerebral cortex in arsenic and lead-induced neurotoxicity in mice ${ }^{39}$.

\section{Conclusion}

HRE prevented the increase in acrylamide-related oxidant and cytokines and the decrease in antioxidants. In addition, HRE has been shown histopathologically to prevent acrylamide-related brain oxidative and inflammatory damage. Based on our experimental results, we think that HRE may be an effective product in preventing acrylamiderelated neurotoxicity. More detailed studies are needed in the future to clarify the protective effect mechanism of HRE against acrylamide-related brain damage.

\section{Authors' contribution}

Conception and design the study: Turan Ml and Suleyman $\mathrm{H}$; Acquisition, analysis and interpretation of data: Suleyman H, Gundogdu B, Aktaş M and Karahan Yılmaz S; Acquisition of data: Suleyman $\mathrm{H}$ and Gundogdu B; Technical procedures: Suleyman $\mathrm{H}$; Manuscript preparation and writing: Suleyman $\mathrm{H}$, Karahan Yllmaz S and Turan Ml; Critical revision: Suleyman H, Turan MI, Gundogdu B, Aktaş M and Karahan Yılmaz S; Final approval of the version to be published: Suleyman H, Turan MI, Gundogdu B, Aktaş M and Karahan Yılmaz S.

\section{Data availability statement}

Data will be available upon request.

\section{Funding}

Not applicable.

\section{Acknowledgments}

Not applicable.

\section{References}

1. Omar MM, Elbashir AA, Schmitz OJ. Determination of acrylamide in Sudanese food by high performance liquid chromatography coupled with LTQ Orbitrap mass spectrometry. Food Chem. 2015;176:342-49. https://doi. org/10.1016/j.foodchem.2014.12.091

2. Boettcher $\mathrm{MI}$, Schettgen $\mathrm{T}$, Kutting $B$, Pischetsrieder $M$, Angerer J. Mercapturic acids of acrylamide and glycidamide as biomarkers of the internal exposure to acrylamide in the general population. Mutat Res. 2005;580:167-76. https:// doi.org/10.1016/j.mrgentox.2004.11.010 
3. Zhang $Y$, Zhang G. Occurrence and analytical methods of acrylamide in heat-treated foods. Review and recent developments. J Chromatogr A. 2005;1075:1-21. https:// doi.org/10.1016/j.chroma.2005.03.123

4. Abramsson-Zetterberg L, Vikstrom AC, Tornqvist $M$, Hellenas KE. Differences in the frequency of micronucleated erythrocytes in humans in relation to consumption of fried carbohydrate-rich food. Mutat Res. 2008;653:50-6. https://doi.org/10.1016/j.mrgentox.2008.03.007

5. Ghanayem BI, McDaniel LP, Churchwell MI, Twaddle NC, Snyder R, Fennell TR, Doerge DR. Role of CYP2E1 in the epoxidation of acrylamide to glycidamide and formation of DNA and hemoglobin adducts. Toxicol Sci. 2005;88:311-8. https://doi.org/10.1093/toxsci/kfi307

6. LoPachin RM, Barber DS, Gavin T. Molecular mechanisms of the conjugated alpha,beta-unsaturated carbonyl derivatives: relevance to neurotoxicity and neurodegenerative diseases. Toxicol Sci. 2008;104:235-49. https://doi.org/10.1093/toxsci/kfm301

7. Tabeshpour J, Mehri S, Abnous K, Hosseinzadeh H. Role of oxidative stress, mapkinase and apoptosis pathways in the protective effects of thymoquinone against acrylamideinduced central nervous system toxicity in rat. Neurochem Res. 2020;45:254-67. https://doi.org/10.1007/s11064019-02908-z

8. Goudarzi M, Mombeini MA, Fatemi I, Aminzadeh A, Kalantari H, Nesari A, Najafzadehvarzi H, Mehrzadi S. Neuroprotective effects of Ellagic acid against acrylamide-induced neurotoxicity in rats. Neurol Res. 2019;41:419-28. https://doi.org/10.1080/01616412.20 19.1576319

9. Shivapriya S, Ilango K, Dubey GP. Evaluation of antioxidant and neuroprotective effect of Hippophae rhamnoides (L.) on oxidative stress induced cytotoxicity in human neural cell line IMR32. Saudi J Biol Sci. 2015;22:645-50. https:// doi.org/10.1016/j.sjbs.2015.04.011

10. Zakynthinos G, Varzakas T. Hippophae rhamnoides: safety and nutrition. Curr Res Nutr Food Sci. 2015;3:89-97. http:// dx.doi.org/10.12944/CRNFSJ.3.2.01

11. Zhao L, Li M, Sun K, Su S, Geng T, Sun H. Hippophae rhamnoides polysaccharides protect IPEC-J2 cells from LPSinduced inflammation, apoptosis and barrier dysfunction in vitro via inhibiting TLR4/NF-kappaB signaling pathway. Int J Biol Macromol. 2019;155:1202-15. https://doi. org/10.1016/j.ijbiomac.2019.11.088

12. Bedir F, Kocatürk H, Yapanoğlu T, Gürsul C, Arslan R, Mammadov R, Çoban A, Altuner D, Suleyman H. Protective effect of taxifolin against prooxidant and proinflammatory kidney damage associated with acrylamide in rats. Biomed Pharmacother. 2021;139:111660. https://doi. org/10.1016/j.biopha.2021.111660

13. Ohkawa H, Ohishi N, Yagi K. Assay for lipid peroxides in animal tissues by thiobarbituric acid reaction. Anal Biochem. 1979;95:351-8. https://doi.org/10.1016/00032697(79)90738-3
14. Bradley PP, Priebat DA, Christensen RD, Rothstein G. Measurement of cutaneous inflammation: estimation of neutrophil content with an enzyme marker. J Invest Dermatol. 1982;78:206-9. https://doi.org/10.1111/15231747.ep12506462

15. Sedlak J, Lindsay RH. Estimation of total, protein-bound, and nonprotein sulfhydryl groups in tissue with Ellman's reagent. Anal Biochem. 1968;25:192-205. https://doi. org/10.1016/0003-2697(68)90092-4

16. Carlberg I, Mannervik B. Glutathione reductase. Methods Enzymol. 1985;113:484-90. https://doi.org/10.1016/ S0076-6879(85)13062-4

17. Yousef MI, El-Demerdash FM. Acrylamide-induced oxidative stress and biochemical perturbations in rats. Toxicology. 2006;219:133-41. https://doi.org/10.1016/j. tox.2005.11.008

18. Kopanska M, Muchacka R, Czech J, Batoryna M, Formicki G. Acrylamide toxicity and cholinergic nervous system. J Physiol Pharmacol. 2018;69(6). https://doi.org/10.26402/ jpp.2018.6.03

19. Vertuani S, Angusti A, Manfredini S. The antioxidants and pro-antioxidants network: an overview. Curr Pharm Des. 2004;14:1677-94. https://doi. org/10.2174/1381612043384655

20. Yasojima EY, Domingues RSZ, Silva RC, Sousa LFF, Júnior SCT. Comparison of remote and local postconditioning against hepatic ischemic-reperfusion injury in rats. Acta Cir Bras. 2021;36(1):e360101. https://doi.org/10.1590/ ACB360101

21. Yanji Xu, Guangzhe Li, Chunji Han, Lianping Sun, Rongjie Zhao, Santian Cui Protective effects of Hippophae rhamnoides L. juice on lead-induced neurotoxicity in mice. Biol Pharm Bull. 2005;28(3):490-4. https://doi. org/10.1248/bpb.28.490

22. Carden DL, Granger DN. Phatophsiology of ischemiareperfusion injury. J Pathol. 2000;190:255-66. https://doi. org/10.1002/(SICI)1096-9896(200002)190:3\%3C255:AIDPATH526\%3E3.0.CO;2-6

23. Aratani Y. 1 Myeloperoxidase: Its role for host defense, inflammation, and neutrophil function. Arch Biochem Biophys. 2018;15(640):47-52. https://doi.org/10.1016/j. abb.2018.01.004

24. Rehring FC, Bui TM, Galán-Enríquez CS, Urbanczyk JM, Ren X, Wiesolek HL, Sullivan DP, Sumagin R. Released myeloperoxidase attenuates neutrophil migration and accumulation in inflamed tissue. Front Immunol. 2021;20(12):654259. https:// doi.org/10.3389/fimmu.2021.654259

25. Ren Q-C, Li X-H, Li Q-Y, Yang H-L, Wang H-L, Zhang $H$, Zhao $L$, Jiang-Yong $S-L$, Meng $X L$, Zhang $Y$, Shen XF. Total flavonoids from sea buckthorn ameliorates lipopolysaccharide/cigarette smoke-induced airway inflammation. Phytother Res. 2019;33(8):2102-17. https://doi.org/10.1002/ptr.6404 
26. Wang ET, Chen DY, Liu HY, Yan HY, Yuan Y. Protective effect of allicin against glycidamide-induced toxicity in male and female mice. Gen Physiol Biophys. 2015;34(2):177-87. https://doi.org/10.4149/gpb_2014038

27. Couto N, Wood J, Barber J. The role of glutathione reductase and related enzymes on cellular redox homoeostasis network. Free Radicl Biol Med. 2016;95:2742. https://doi.org/10.1016/j.freeradbiomed.2016.02.028

28. Jurkovic S, Osredkar J, Marc J. Molecular impact of glutathione peroxidases in antioxidant processes. Biochem Med. 2008;18:162-74. https://doi.org/10.11613/ BM.2008.016

29. Gupta R, Flora SJS. Therapeutic value of Hippophae rhamnoides $L$. against subchronic arsenic toxicity in mice. J Med Food. 2005;8(3):353-61. https://doi.org/10.1089/ jmf.2005.8.353

30. Maheshwari DT, Kumar MYS, Verma SK, Singh VK, Singh SN. Antioxidant and hepatoprotective activities of phenolic rich fraction of Seabuckthorn (Hippophae rhamnoides L.) leaves. Food Chem Toxicol. 2011;49(9):2422-8. https://doi. org/10.1016/j.fct.2011.06.061

31. Padmavathi B, Upreti M, Singh V, Rao AV, Singh RP, Rath PC. Chemoprevention by Hippophae rhamnoides: effects on tumorigenesis, phase II and antioxidant enzymes, and IRF-1 transcription factor. Nutr Cancer. 2005;51(1):59-67. https://doi.org/10.1207/s15327914nc5101_9

32. Ye L, Huang Y, Zhao L, Li Y, Sun L, Zhou Y, Qian G, Zheng JC. IL-1beta and TNF-alpha induce neurotoxicity through glutamate production: a potential role for neuronal glutaminase. J Neurochem. 2013;125:897-908. https://doi. org/10.1111/jnc.12263
33. LoPachin RM, Gavin T. Molecular mechanism of acrylamide neurotoxicity: lessons learned from organic chemistry. Environ Health Perspect. 2012;120:1650-7. https://doi. org/10.1289/ehp.1205432

34. Erhan E, Terzi S, Celiker M, Yarali Oguzhan, Cankaya M, Keskin Cimen F, Malkoc I, Suleyman B. Effect of hippophae rhamnoides extract on oxidative oropharyngeal mucosal damage induced in rats using methotrexate. Clin Exp Otorhinolaryngol. 2017;10(2):181-7. https://doi. org/10.21053/ceo.2016.00262

35. Balkrishna A, Sakat SS, Joshi K, Joshi K, Sharma V, Ranjan R, Bhattacharya K, Varshney A. Cytokines driven anti-inflammatory and anti-psoriasis like efficacies of nutraceutical sea buckthorn (Hippophae rhamnoides) Oil. Front Pharmacol. 2019;11(10):1186. https://doi. org/10.3389/fphar.2019.01186

36. Suryakumar G, Gupta A. Medicinal and therapeutic potential of Sea buckthorn (Hippophae rhamnoides L.). J Ethnopharmacol. 2011;138:268-78. https://doi. org/10.1016/j.jep.2011.09.024

37. Noonan DM, De Lerma Barbaro A, Vannini N, Mortara L, Albini A. Inflammation, inflammatory cells and angiogenesis: decisions and indecisions. Cancer Metastasis Rev. 2008;27:31-40. https://doi.org/10.1007/s10555-0079108-5

38. Kim YW, West XZ, Byzova TV. Inflammation and oxidative stress in angiogenesis and vascular disease. J Mol Med. 2013;91(3):3238. https://doi.org/10.1007/s00109-013-1007-3

39. Gupta R, Flora SJ. Protective effects of fruit extracts of Hippophae rhamnoides L. against arsenic toxicity in Swiss albino mice. Hum Exp Toxicol. 2006;25:285-95. https://doi. org/10.1191/0960327106ht636oa 